\title{
Heat-No-Service: Reproductive lifetime performance of gilts inseminated on first versus second observed estrus in commercial piglet producing herds
}

\author{
Joab Malanda ${ }^{1}$ - Péter Balogh ${ }^{2}$ - Gabriella Novotni Dankó ${ }^{1}$ \\ ${ }^{1}$ Department of Animal Husbandry, Faculty of Agricultural and Food sciences and Environmental Management. \\ University of Debrecen, Hungary \\ ${ }^{2}$ Institute of Sectoral Economics and Methodology, Faculty of Economics and Businesses. \\ University of Debrecen, Hungary \\ mtolivet.livet@gmail.com
}

SUMMARY

Heat No Service (HNS) is an increasing managerial decision made in commercial piglet producing herds. Performance of gilts has been shown to be influenced by initial decisions made on them at their introduction in the breeding herds. Lifetime Reproductive performance comprising of parity total born piglets and lifetime total born piglets of gilts initially bred on first observed estrus (OHNS) was compared with that of gilts bred on second observed estrus (1HNS). Stored data from Porcitec database consisted of 2.072 gilts bred on first observed estrus (OHNS) and 2.453 gilts bred on second observed estrus (1HNS) totaling to 4.525 gilts. Data was statistically analyzed using the GLM procedure of IBM SPSS version 25. The results showed a significance difference ( $p<0.001)$ in lifetime total born performance of gilts bred at 0HNS (mean 93.9) and 1HNS (mean 95.7). There was also a significant difference ( $p<0.001)$ of total born piglets in parity 1, 5 and 6 in the 2 groups. There was an observed increased parity total born and lifetime total born when first time insemination of gilts was delayed to second estrus. The findings in this study favor the 1HNS breeding with an overall increased lifetime total born. Gilts inseminated at 1 HNS produce 1.57 more pigs for lifetime as compared with those inseminated at OHNS when observation is made up to P6. Producers in piglet producing herds could re examine their decisions for increased productivity by promoting many gilts into 1HNS but still maintaining the balance between breed targets and production schedules to remain competitive and profitable in the current global swine industry.

Keywords: Gilts, Estrus, Heat No Service, Total born, Lifetime performance

\section{INTRODUCTION}

Gilts constitute a significant proportion of the breeding females $(20 \%-25 \%)$ in most herds, and decisions made on gilts are likely to have a significant effect on overall herd performance and profitability (Sporke, 2005). Heat No Service (HNS) is a voluntary managerial decision by identification of pubertal estrus gilts without breeding and is influenced by (i) Physiological status of the gilt (age, body weight and backfat thickness at first service) (ii) Rate of sow replacement/culling in the herd and (iii) Production schedules. In most farm management scenarios, the identified HNS gilts enter the breeding pool and may remain in their pen or be relocated to another pen. Several studies have evaluated the influence of age, weight, backfat thickness, nutrition, boar exposure, genetics and seasonality on the attainment of puberty and reproductive performance in gilts (Dyck, 1971; Kirkwood and Aherne, 1985; Elliason et al., 1991; Irgang et al., 1993; Bidanel et al., 1996; Evans and O'Doherty, 2001; Wettere et al., 2006; Tummaruk et al., 2009; Malanda et al., 2019), however no studies have examined the influence of Heat No Service on subsequent lifetime reproductive performance.

Heat detection and breeding timing are very important since knowing both non-heat behavior and heat behavior makes it easier to identify when a gilt is coming into receptive heat for breeding. Ideally, breeding occurs during a time called 'standing heat' at which time the female will 'lock up', exhibiting a natural behavior of standing rigidly and be receptive to mounting by a boar. Pork producers are frequently advised to delay the breeding of gilts until they are 8 months old and have shown the first estrus (Field and Taylor, 2012). This is based on the fact that prolificacy is enhanced since ovulation rate increases to second estrus (Anderson and Einarsson, 1980; Brooks et al., 1980; Vinsky et al., 2006). Controlled experiment research demonstrated that gilts mated at first estrus produced fewer piglets than counterparts mated at third estrus (MacPherson et al., 1977; Young et al., 1990) However in Young and King's (1981) study, sows mated in first and third estrus were allowed to complete three parities and showed no substantial difference in total productivity.

Reproductive lifetime performance evidence in support of HNS has not been evaluated, therefore the objective of this research was to compare the influence of inseminating at the first observed estrus (0 Heat No Service) versus second observed estrus (1 Heat No Service) on lifetime reproductive performance over six parities of gilts.

\section{MATERIALS AND METHODS}

Animal Welfare and Ethics Committee approval was not obtained for this study because the data used for this analysis was obtained from a private company's existing Porcitec database. (www.agritecsoft.com). Gilts were purchased from multiplier herds within the US and Canada and transported to the selected farms for gilt development and subsequent artificial insemination either on the first or second estrus after boar exposure. Gilts in the selected farms were managed under similar management operations in all 
the farms hence no herd effect was put in consideration during our analysis. To be included in the present study, the herds were selected on their merit of completeness and accuracy of recording data.

Data consisted of F1 Landrace x Yorkshire gilts entered in the herds from $1^{\text {st }}$ Jan 2014 until $31^{\text {st }}$ July 2016. The individual records of all sows which presently have been culled were used, so that their entire productive life was included in this analysis. The selected breed -wean farms were located in the Midwest of the United States. The following information was extracted from the database; gilt ID, first observed estrus insemination (0HNS), second observed estrus insemination(1HNS), parity total born piglets and lifetime total born piglets. Gilts, designated as parity $0(\mathrm{P} 0)$, were excluded from the analysis and sows greater than parity 6 (P6) were excluded since the private company's policy stipulates culling of P6 and older sows. All sows with missing values in the dataset were excluded and the final data set containing 2.072 gilts bred on first observed estrus (OHNS) and 2.453 gilts bred on second observed estrus (1HNS) totaling to 4.525 gilts was exported as excel-file into IBM SPSS Statistics version 25 (IBM SPSS Inc, Armonk NY., USA) where all statistical analysis was obtained.

Data was statistically analyzed using the GLM procedure of IBM SPSS version 25 . The study used the model of:

$$
\mathrm{LTP}_{\mathrm{ijklm}}=\mu+\text { PAR1-6 } \mathrm{i}+\mathrm{HNS}_{1}+\varepsilon_{\mathrm{ijklm}}
$$

where:

LTP $_{\mathrm{ijklm}}$ - Lifetime total pigs as a dependent variable; $\mu$ - overall mean; PAR1-6 as a main effects;
$\mathrm{HNS}_{\mathrm{l}}-$ Heat No Service as a main effect; $\varepsilon_{\mathrm{ijklm}}-$ Random Error.

\section{RESULTS}

The obtained results show a significant $(\mathrm{p}<0.001)$ for HNS on both groups (Table 3). The standard deviation of lifetime total pigs was 13.250 and 13.047 for $0 \mathrm{HNS}$ and 1HNS respectively (Table 1). Table 1 shows a higher mean lifetime total pigs of 95.47 for 1HNS as compared to 93.90 for 0 HNS. In Table 2 there is a gradual increase of parity total born from $\mathrm{P} 1-\mathrm{P} 4$ and a decline from P5-P6 for 0HNS while a similar increase is realised up to P5 for 1HNS and a decline seen in P6. As seen in Table 1, most gilts were inseminated in the 1HNS $(\mathrm{n}=2453)(54.2 \%)$ as compared to OHNS $(n=2072)(45.8 \%)$. The parity increase in pigs per litter within the two groups ranged from -0.06 to +0.66 when insemination was delayed until second observed estrus (1HNS).

Table 1

Descriptive statistics of HNS dependent on lifetime total pigs

\begin{tabular}{|c|c|c|c|c|}
\hline & $\mathrm{N}$ & Mean & Std.dev & $\%$ \\
\hline $\begin{array}{l}\text { Inseminated on First estrus } \\
\text { (0HNS) }\end{array}$ & 2072 & 93.90 & 13.250 & 45.8 \\
\hline $\begin{array}{l}\text { Inseminated on Second } \\
\text { estrus (1HNS) }\end{array}$ & 2453 & 95.47 & 13.047 & 54.2 \\
\hline Total & 4525 & 94.75 & 13.162 & 100 \\
\hline
\end{tabular}

Descriptive statistics of HNS dependent on lifetime total pigs within parities

\begin{tabular}{llccccccc}
\hline & & Parity 1 & Parity 2 & Parity 3 & Parity 4 & Parity 5 & Parity 6 & Lifetime pigs \\
\hline Inseminated on & N of sows & 2072 & 2072 & 2072 & 2072 & 2072 & 2072 & 2072 \\
First observed & Mean pigs & 14.34 & 15.00 & 16.00 & 16.46 & 16.41 & 15.69 & 93.90 \\
Estrus (0HNS) & Std dev & 2.876 & 3.287 & 3.329 & 3.397 & 3.552 & 3.973 & 13.250 \\
\hline Inseminated on & N of sows & 2453 & 2453 & 2453 & 2453 & 2453 & 2453 & 2453 \\
Second observed & Mean pigs & 14.62 & 14.94 & 16.07 & 16.63 & 16.88 & 16.35 & 95.47 \\
Estrus (1HNS) & Std dev & 2.736 & 3.386 & 3.374 & 3.486 & 3.419 & 3.780 & 13.047 \\
\hline \multirow{3}{*}{ Total } & N of sows & 4525 & 4525 & 4525 & 4525 & 452 & 4525 & 4525 \\
& Mean pigs & 14.49 & 14.96 & 16.04 & 16.55 & 16.67 & 16.05 & 94.75 \\
& Std dev & 2.804 & 3.341 & 3.353 & 3.446 & 3.488 & 3.883 & 13.162 \\
\hline
\end{tabular}

Table 3

ANOVA Test between groups combined

\begin{tabular}{lccc}
\hline \multicolumn{1}{c}{ Source } & mean square & $\mathrm{F}$ & sig \\
\hline Parity $1 * \mathrm{HNS}$ & 85.788 & 10.933 & 0.001 \\
Parity 2*HNS & 4.174 & 0.374 & 0.541 \\
Parity 3*HNS & 4.768 & 0.424 & 0.515 \\
Parity 4*HNS & 33.985 & 2.862 & 0.091 \\
Parity 5*HNS & 243.973 & 20.141 & 0.000 \\
Parity 6*HNS & 477.514 & 31.892 & 0.000 \\
LTP*HNS & 2777.718 & 16.087 & 0.000 \\
\hline
\end{tabular}

Significant at the $\mathrm{P}<0.001$ level

\section{DISCUSSION}

The current swine industry has continuously pushed for increased production in terms of total born pigs. Our results indicate that gilts inseminated at second observed estrus (1HNS) produced 1.57 more pigs per lifetime as compared to those inseminated on first observed estrus (0HNS). It appears that 1HNS is the appropriate estrus for insemination that can result in an increased lifetime total born. Since total born pigs is directly proportional to ovulation rate, our results are supported by (Dyck, 1971a; Vinsky et al., 2006) who found out that ovulation rate usually increases from 
first to second and third estrus implying that the number of embryos also increases from first estrus to second estrus. However in another study done by Eastham et al. (1986) the number of live embryos decreased by delaying mating until second estrus compared to first estrus. As seen in Table 2, parity total born pigs increases from $\mathrm{P} 1-\mathrm{P} 4$ in both groups, similar findings recorded by (Clark et al., 1988; Iida and Koketsu, 2014; Gruhort et al., 2017) who noted an increasing litter size till parity 4 . There is a notable decline in parity total born in both groups from P5-P6 (Table 2) for 0HNS, a finding that is also supported by Tummaruk et al. (2001) who observed a decline in parity total born from P5-P7. This findings could explain the fact that when sows are still young in the herds (P1-P4) they are at their best in terms of physiological and vitality to produce as compared to ageing sows at $>$ P5. The significant $(\mathrm{p}<0.001)$ difference of lifetime total pigs seen in parity 1, 5 and 6 (Table 3 ) could be explained by the fact that P1s with small uterine capacity tend to have a low total born in their first reproductive performance. As P1s continues to grow there is an increase in uterine size which increases the number of offsprings obtained because the uterine horn length is positively correlated with ovulation rate (Chen et al., 1993; Vianna et al., 2004) hence uterine size is an important limiting factor affecting litter size at birth. Consequently, a reduced total born farrowing productivity seen in P5 \& P6 is an indicator of decreased farrowing productivity performance with increase in age, a similar finding made by (de Jong et al., 2014; Malanda et al., 2019).

HNS is highly affected by scheduling of gilts for production purpose. Scheduling of breeding sows helps to optimize their needs, streamline management and marketing can be planned. In this study 0HNS representing $45.8 \%$ of the gilts were inseminated on first estrus. Swine production has become highly competitive and producers continuously seek for increased production with emphasis on cost reduction. This substantial amount of gilts on OHNS could be explained by the fact that, maintaining gilts until second observed estrus could be viewed as a costly venture since there is a requirement of feed and accommodation for approximately 21 additional days before breeding, hence swine producers could aim at cutting costs by inseminating the gilts on OHNS. Furthermore, modern US swine production has been experiencing an annual increasing culling rate of up to $50 \%$ (Hoge and Bates, 2011), with this increasing cull rates, the percentage of breeding gilts increases, resulting in a larger proportion of gilts being bred to replace the culled sows in production.

\section{CONCLUSION}

It is concluded that gilts that are inseminated at 1HNS (second observed estrus) tend to produce 1.57 more pigs for lifetime as compared with those inseminated at OHNS (first observed estrus) when observation is made up to parity 6 . This is the first study of its kind to put to perspective the relationship of HNS with lifetime total born pigs. In swine production, decisions made on gilts prior to their introduction in the breeding herds have been found to have profound effects on lifetime performance. Deciding whether to uphold OHNS or 1HNS has now been shown to have a significant $(p<0.001)$ on lifetime total born of the sows. Swine producers in piglet producing herds can now decisively push more gilts into the 1HNS for increased parity and lifetime total born as shown from this study.

Though the present study was an observational analysis of records from commercial farms. Farm data analysis using appropriate exclusion criteria and multilevel statistical models can disseminate practical and readily applicable information to swine producers about production issues that are difficult to investigate under controlled experiments. The findings in this study provide valuable information and adds to scientific work which swine producers and veterinarians can directly apply for practice and productivity in the swine industry.

\section{ACKNOWLEDGEMENTS}

The authors gratefully thank the swine producer for their cooperation in providing their valuable data for use in this study.

\section{AVAILABILITY OF DATA AND MATERIALS}

The dataset analyzed during the current study is not publicly available to protect producers' privacy and farm details.

\section{ETHICS APPROVAL}

Not applicable.

\section{CONFLICT OF INTEREST}

The authors declare no conflict of interest.

\section{REFERENCES}

Anderson, A. M.-Einarsson, S. (1980): Studies on the estrus and ovarian activity during five successive estrus cycles in gilts. Acta Vet. Scand.21: 677-688.

Bidanel, J. P.-Gruand., J.-Legault. C. (1996): Genetic variability of age and weight at puberty, ovulation rate and embryo survival in gilts and relations with production traits. Genet Sel Evol. 28:103-115.
Brooks, P. H.-Smith, D. A. (1980): The effect of mating age on the reproductive performance, food utilization and live weight change of the female pig. Livest. Prod. Sci. 7, 67-78.

Chen, Z. Y.-Dziuk, P. J. (1993): Influence of initial length of uterus per embryo and gestation stage on prenatal survival, development, and sex ratio in the pig. J Anim Sci. 71:1895-1901. 
Clark, L. K.-Leman, A. D.--Morris, R. (1988): Factors influencing litter size in swine: parity-one females. J. Am. Vet. Med. Assoc. 192, 187-194.

De Jong, E.-Appeltant, R.-Cools, A.-Beek, J.-Boyen, F.-Chiers K.-Maes, D. (2014): Slaughterhouse examination of culled sows in commercial pig herds. Livest. Sci., 167: 362-369.

Dyck, G. W. (1971): Ovulation rate and weight of the reproductive organs of Yorkshire and Lacombe swine. Can J. Anim. Sci. 51: 141-146.

Eastham, P. R.-Dyck, G. W.-Cole, D. J. A. (1986): Reproduction in the gilt. 6 . The effect of various degrees of mature boar contact during rearing on puberty attainment. Animal Production 43: 341-349.

Eliasson, L.-Rydhmer, S.-Einarsson, S.-Andersson, K. (1991): Relationship between puberty and production traits in the gilt. Age at puberty. Anim. Reprod. Sci. 25, 143-154.

Evans, A. C. O.-O'Doherty, J. V. (2001): Endocrine changes and management factors affecting puberty in gilts. Livestock Production Science. 68:1-12.

Field, G.-Taylor, E. (2012): Scientific Farm Animal Production: An Introduction to Animal Science .Tenth edition page Published by Pearson Prentice Hall. pp 495.

Gruhort, T. R.-Chalderon, D. A.-Baas, T. J.-Stalder, K. J. (2017) Using first and second parity number born alive information to estimate later reproductive performance in sows. Livestock Science 196:22-27.

Hoge, M. D.-Bates, R. O. (2011): Developmental factors that influence sow longevity. Journal of Animal Science. 89:12381245.

Iida, R.-Koketsu, Y. (2014): Interactions between pre- or postservice climatic factors, parity, and weaning-to-first-mating interval for total number of pigs born of female pigs serviced during hot and humid or cold seasons. Journal of Animal Science. 92:41804188.

Irgang, R.-Scheid, I. R.-Wentz, I. V. O.-Favero, J. A. (1993): Ovulation rate, embryo number and uterus length in purebred Duroc, Landrace and Large White gilts. Livest Prod Sci. 33:253266.

Kirkwood, R. N.-Aherne, F. X. (1985): Energy intake, body composition and reproductive performance of the gilt. Journal of Animal Science. 60: 1518-1529.
MacPherson, R. M.-DeB. Howell., F.-Jones, A. S. (1977): Performance of sows first mated at puberty or second or third estrus, and carcass assessment of once-bred gilts. Anim. Prod. 24:333-342.

Malanda, J.-Balogh, P.-Novotni Danko., G. (2019): Optimal age of breeding gilts and its impact on lifetime performance. Acta Agraria Debreceniensis, (2), 15-20. https://doi.org/10.34101/actaagrar/2/3672

Sporke, J. (2005): Gilt Development Programs in North and South America. American Association of Swine Veterinarians (AASV), Toronto, Canada, pp. 11-16.

Tummaruk, P.-Lundeheim, N.-Einarsson, S.-Dalin, A. M. (2001): Effect of birth litter size, birth parity number, growth rate, backfat thickness and age at first mating of gilts on their reproductive performance as sows. Animal Reproduction Science, vol. 66, ss. 225-237.

Tummaruk, P.-Tantasuparuk, W.-Techakumphu, M.-Kunavongkrit, A. (2009): The association between growth rate, body weight, backfat thickness and age at first observed estrus in crossbred Landrace $\times$ Yorkshire gilts. Animal Reprod Sci. 110:108-122.

Vianna, W. L.-Pinese, M. E.-de Campos Rosseto, A.-Bombonato, P. P.-Rodriguez, P. H. M.-de Sant'Anna Moretti, A. (2004): Relationship between prenatal survival rate at 70 days of gestation and morphometric parameters of vagina, uterus and placenta in gilts. Reprod Domest Anim. 39:381-384.

Vinsky, M. D.--Novak, S.-Dixon, W. T.-Dyck, M. K.-Foxcroft, G. R. (2006): Nutritional restriction in lactating primiparous sows selectively affects female embryo survival and overall litter development. Reprod Fertil Dev. 18:347-355.

Wettere, W. H.--Revell, D. K.-Mitchell, M.-Hughes, P. E. (2006): Increasing the age of gilts at first boar contact improves the timing and synchrony of the pubertal response but does not affect potential litter size. Animal Reproduction Science. 95:97-106.

Young, L. G.-King, G. J. (1981): Wheat shorts in diets of gestating swine. J. Anim. Sci. 52:551.

Young, L. G.-King, G. J.-Walton, J. S.-McMillan, I.-Klevorick, M. (1990): Age, weight, backfat and time of mating effects on performance of gilts. Can. J. Anim. Sci. 70: 469-481. 